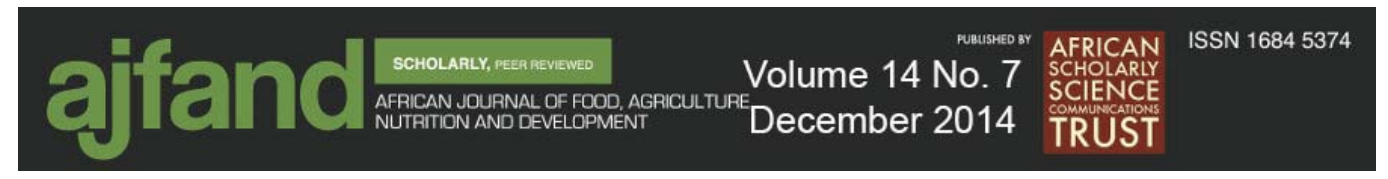

\title{
NUTRACEUTICAL PERSPECTIVES AND UTILIZATION OF COMMON BEANS (PHASEOLUS VULGARIS L.): A REVIEW
}

Nyau $V^{1 *}$

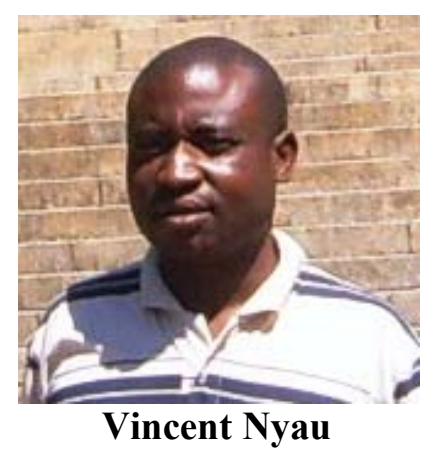

*Corresponding author email: vincentnyau@yahoo.co.uk

${ }^{1}$ Department of Food Science and Technology, School of Agricultural Sciences, University of Zambia, P. O. Box 32379, Lusaka, Zambia 


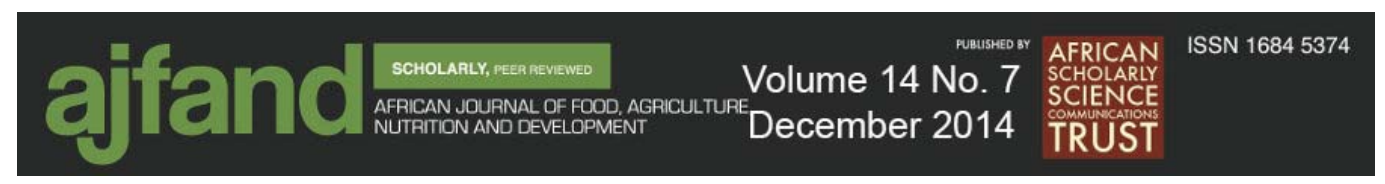

\begin{abstract}
Consumers are increasingly becoming aware of the health benefits of foods and pay particular attention to the potential disease preventing and health promoting compounds that a given food contains. This awareness, coupled with a well-known understanding of how diet affects our health is motivating a quest for natural health products. There is a growing interest in common beans and their products because of the health claims associated with their consumption. Common beans are rich in protein, carbohydrate, fiber, minerals and vitamins. Proteins have always been recognized as the most significant macronutrient in common beans and though the seed is limited in methionine (a sulphur containing amino acid), it is often complemented by methioninerich cereal sources such maize and wheat. Consumption of common beans has been linked to decreased occurrence of chronic non communicable diseases such diabetes, cancer, obesity and coronary heart diseases. Common beans contain a variety of phytochemicals such as polyphenolic compounds, alkaloids, fibre, saponins, steroids, lectins and terpenoids among others. These phytochemicals are believed to offer protective functions and physiological effects in the body. The nutraceutical properties that have been described for common beans include free radical scavenging activity, glycemic index lowering activity, anti-lipase activity, anti-mutagenic activity, cancerpreventive activity, lowering of the plasma cholesterol levels and antioxidant activity. The objective in this paper is to review the major biological activities of common beans as reported in the literature. The paper also reports on the opportunities to use common beans in the formulation of ready-to-use products or products that are quick to prepare in order to increase its utilisation in both the developed and developing countries. It is well understood that one of the factors that discourages consumption of common beans and other legumes is long cooking time. Ready-to-use products or products with short preparation times provide an opportunity for convenient consumption of common beans by consumers in busy occupations.
\end{abstract}

Key words: Nutraceuticals, Common beans, Health benefits 


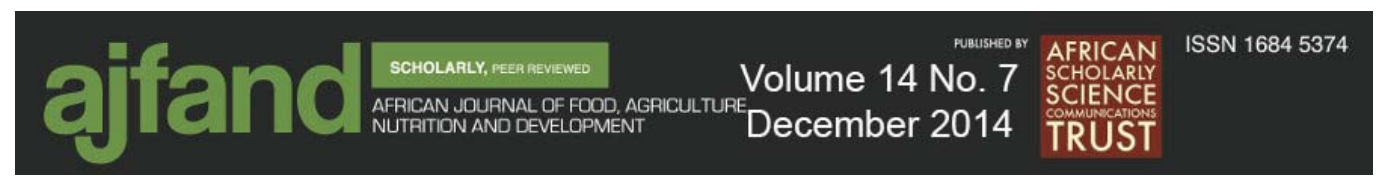

\section{INTRODUCTION}

Among the commonly consumed food legumes in the world, common beans (Phaseolus vulgaris L.) occupy an important position in human nutrition. The regions of highest bean consumption include all of Latin America, Sub-Sahara Africa, which utilizes dry beans and other legumes (example. cowpea and bambara beans), and the subcontinent of India which uses the greatest quantity [1]. Throughout Southeast Asia, consumption of legumes is moderate and a great variety of species are produced and used as mature seeds and immature vegetative pods. The per capita consumption of legume-based food products in the United States, Europe (encompassing the EU) and other industrialized economies has generally and consistently been substantially lower than that observed in other regions of the world [1]. Common beans provide an economical source of proteins, especially among the low income group who cannot afford the more expensive meat proteins. Legume-based foods are also one of the best non-meat sources of iron, providing $23-30 \%$ of daily recommended levels [2]. A high degree of diversity in terms of colour, size, growth habits and seed shape is present in P. vulgaris. However, names like pinto beans, red kidney beans, white beans and black beans are frequently encountered in many growing regions.

There is a growing interest in common beans and other food legumes because they have been linked to conveying various positive responses when appropriately positioned in the diet. There is growing evidence that cereals and legumes play important roles in the prevention of chronic diseases and that overall, the substantial epidemiological evidence of legumes in chronic diseases is very promising [3]. Consumption of common bean has been associated with reduced risk of some diseases such as coronary heart and cancer [4]. The physiological effects of common bean may be due to the presence of abundant phytochemicals including polyphenols, which possess both anticarcinogenic and antioxidant properties [4]. Common beans, like other legumes also contain high fibre contents. Research has demonstrated that increased consumption of dietary fibre and resistant starch that are available from dry beans produce specific physiological responses that are of health significance [1]. Some of the health benefits associated with high fibre diets may come from other components, not just from the fibre itself but hundreds of unidentified phytochemicals, such as phytoestrogens, antioxidants, and phenols, which together with vitamins and minerals such as vitamin $\mathrm{E}$ and selenium may play important roles in disease prevention [5]. These health benefits are achieved through multifactorial physiological mechanisms including antioxidant activity, hormonal mediation, immune system enhancement, facilitation of substance transit through the digestive tract, butyric acid production in the colon, and absorption and/or dilution of substances in the gut [6]. The potential for common beans as nutraceuticals is thus very promising. Nutraceuticals are food components that provide health benefits in addition to their basic nutritional value [7].

\section{Phytochemicals in common beans}

Basic qualitative screening for common beans has shown that alkaloids, anthraquinone, catechitannins, flavonoids, tannins, glucosides, polyphenols, saponins, steroids and terpenoids are present [8]. Phytochemical screening showed the presence of some 
bioactive components such as alkaloids, anthocyanin, carbohydrate, catechin, fibers, flavonoids, phasine, phytic acid, quercetin, saponins, steroids, tannins and terpenoids and trypsin inhibitor [8]. Analysis using HPLC-MS, identified compounds such as anthocyanins, flavanol monomers, and heterogeneous flavanol oligomers up to hexamers [8]. The presence of catechin, delphinidin, cyaniding, and phenolic acids such as gallic, vanillic, caffeic, coumaric and ferrulic in the seed coat of common beans have been reported [9]. Phenolic compounds such as antocyanins, quercetin glycosides and protoanthocyanidins (condensed tannins), were isolated and identified in dark red kidney beans [10]. Kaempferol and quercetin have been reported as the main flavonoids in different market classes of Mexican beans [11]. The chemical structures of some of the compounds that were identified in common beans are presented in Table 1.

The nutraceutical benefits of some of the identified phytochemicals have been previously described. An inverse correlation between flavonoid intake and total plasma cholesterol concentrations has been shown [12]. Flavonoid intake has also been reported to have a protective effect against coronary heart disease [13, 14). Quercetin has been shown to have anti-inflammatory properties and do so by inhibiting the cyclooxygenase pathway [15]. Quercetin has also been shown to inhibit the growth of Helicobacter pylori bacteria in in-vitro studies [14]. Methyl-3-(+)-catechin interferes with the formation of histamine in gastric mucosa and hence produces a protective effect [16]. Most flavonoids have anti-viral effects against Herpes simplex virus, respiratory syncytial virus, parainfluenza virus, and adenovirus [15]. Flavonoids have also been shown to have free radical scavenging properties [17].

\section{Antioxidant activity of common beans}

Antioxidants are very important compounds that protect the body against damages caused by free radical reactions. They offer this protective function by getting oxidised themselves. Free radicals are atoms or molecules or ions with unpaired valence electrons. They are very unstable and react very quickly with other molecules or radicals to achieve a stable configuration. Free radicals are generated through normal body metabolism, environmental factors such as pollution, radiation, pesticides and cigarette smoke in which oxygen participates in the reaction. Extreme amount of free radicals attack cellular components such as DNA, lipids and proteins which is thought to be an initiating factor for several chronic diseases [18]. Dietary antioxidants may prevent these cellular components from oxidative damage and consequently reduce the risk of age related diseases [19]. The antioxidant activity of common beans has been previously investigated using different methods. Studies on the antioxidant activity of more than 100 food items using the Oxygen Radical Absorbance Capacity (ORAC) assay reported common beans (navy, black, pinto, red kidney and small red) among the food items evaluated to have the highest antioxidant activity [20]. A study on antioxidant potential of a methanol extract, acetate/acetone and acetone fractions from common beans using the $\beta$-carotene-linoleate and the 1,1-diphenyl-2- picrylhydrazyl (DPPH) assays demonstrated varying antioxidant activities which were concentration dependent [21]. Pure flavonoid compounds such as anthocyanins, quercetin glycosides and protoanthocyanidins (condensed tannins) in the seed coat methanol extract and tannin fractions from 10 colored genotypes of common bean all demonstrated 


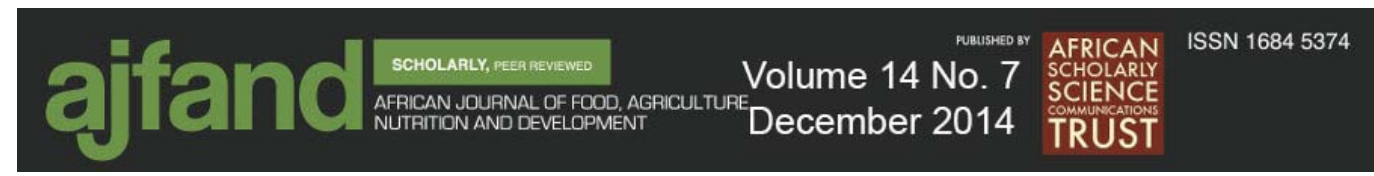

antioxidant activity, with the highest activity reported in extracts that were rich in condensed tannins [10].

\section{Common beans and colon cancer}

There is substantial scientific evidence that regular consumption of common beans and other legumes reduces the risks of colon cancer. Epidemiological studies show a low incidence of colon cancer in many Latin American countries where the consumption of common beans is high [22]. The effect of common beans on the inhibition of colon cancer induced by the carcinogen, azoxymethane (AOM) in rats has been previously investigated [23]. At 31 weeks after the second AOM injection, the incidence of colon adenocarcinomas was significantly lower in rats fed the black beans $(9 \%)$ and navy beans $(14 \%)$ than in rats fed the control diet $(36 \%)$. The study thus demonstrated that common beans contain anticarcinogenic components capable of inhibiting AOMinduced colon cancer. However, the specific anticarcinogenic component has not been identified and it is not clear whether dietary fibre, phytochemicals or other components within dry beans are responsible for this effect. Many theories have been offered to explain the protective effect of foods such as legumes and whole grains on the colon. These foods contain fermentable carbohydrates, including dietary fibre, resistant starch and oligosaccharides. Indigestible carbohydrates reach the colon and are fermented by intestine microfloara to short chain fatty acids such as acetate, butyrate, propionate, which have been associated with lowered serum cholesterol and decreased risk of cancer [24]. Legumes contain several antinutrients such as protease inhibitors, phytic acid, phenolics and saponins. These antinutrient compounds may act as cancer inhibitors by preventing the formation of carcinogens and by blocking the interaction of carcinogens with cells [25]. The antioxidant properties may also be important in cancer prevention [26].

\section{Common beans and blood glucose}

Legume starch is more slowly digested than starch from most other sources. Low glycemic responses have been observed for legumes compared with other starchy foods such as bread, potato and certain breakfast cereals [1]. Food with low glycemic indexes produce small rise in blood sugar and may be beneficial to diabetic patients. Low-GI diets improved adipocyte insulin-mediated glucose uptake in vitro and was found to be useful in normalizing diet-insulin responses of hyperinsulinaemic subjects [27]. Five different varieties of beans, both cooked and canned were found to have lower mean glycemic index $(\mathrm{GI}=47)$ than white bread $(\mathrm{GI}=100)$ when fed to a group of diabetic patients [28]. On the other hand, the rate of hydrolysis of starch from black beans is markedly slower (41\%) compared with white bread (50\%) [29]. A study on plasma glucose and satiety has reported a sharp rise in plasma glucose levels after a meal containing potato, and in contrast, a slow sustained increase in blood glucose after consumption of bean puree [30]. 


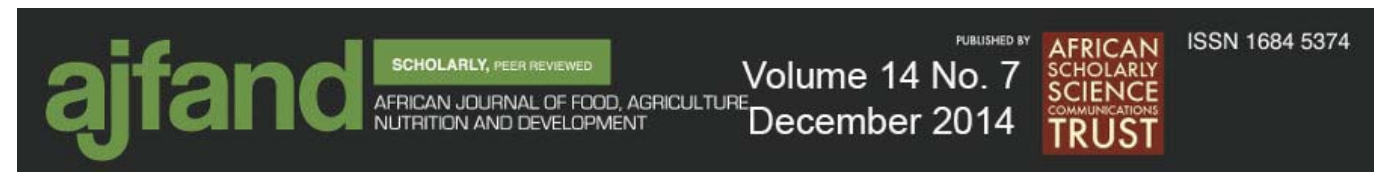

\section{Common beans and obesity/weight management}

Obesity is a major health problem in industrialized nations and a new threat among the middle class in developing countries. This condition is a risk factor for many diseases such as diabetes, cardiovascular disease and some forms of cancer. It is associated with a state of chronic inflammation characterised by abnormal production of inflammatory cytokines and acute phase reactants [31]. Low glycemic index diet might also protect against the development of obesity [32]. Research has demonstrated links between overweight and reduced fibre consumption. People of normal weight consumed on average $19 \mathrm{~g}$ of fibre daily whereas obese people consumed only $13 \mathrm{~g}$ of fibre daily [33]. Beans have been noted as a food that can contribute to weight management due to the relative low glycemic index, high resistant starch and high satiety level [30]. The potential use of resistant starch in weight management has been previously discussed [34].

\section{Common beans and cardiovascular disease}

Cardiovascular disease (CVD) is a major health concern in the world and one of the leading causes of death and disability. Epidemiological evidence shows that regular consumption of beans reduces the risk of coronary heart disease. After adjusting for confounding factors, individuals consuming legumes at least 4 times per week were found to have $22 \%$ lower risk of heart disease than individuals consuming legumes less than once per week [35]. According to the findings in the Health Professional Followup study, men that adhered to a more prudent diet, which included greater consumption of whole grains, legumes, fish, and poultry had a $30 \%$ lower risk of having heart disease [36]. In contrast, individuals following a more western diet, characterized by increased consumption of red meat, refined grains, sweets, French fries, and high fat desserts had over $30 \%$ higher risk of heart disease [36].

The amount of total cholesterol in the plasma may influence the risk of developing heart disease. A $1 \%$ reduction in total cholesterol has been reported to correspond to about a $2 \%$ decrease in the risk of developing heart disease [37]. A regular consumption of beans may contribute to lowering the plasma cholesterol levels $([38,39]$. The inclusion of $450 \mathrm{~g}$ baked beans into the daily diet of normocholesterolaemic men resulted in a significant reduction in the mean plasma cholesterol level from 5.1 to $4.5 \mathrm{mmol} / \mathrm{l}$ within 1 week. In contrast, no reduction in plasma cholesterol was observed when $440 \mathrm{~g}$ spaghetti with tomato sauce was included in the daily diet of the same subjects for 2 more weeks [39]. Beans are a good source of soluble dietary fibre, containing approximately $4 \mathrm{~g}$ per 1 cup cooked portion [38]. Soluble fibre from different fibre sources is associated with small but significant decrease in total cholesterol [40]. The hypocholesterolemic effect of dietary fibre has been attributed to its ability to inhibit intestinal absorption of bile acids and neutral steroids, resulting in greater faecal bile acid and total steroids excretion [41]. Resistant starch, which is part of the dietary fibre family, has gelling and bile acids binding properties, thus increasing viscosity of intestinal contents and reducing bile acids absorption [42]. On the other hand, butyratedependent acceleration of fecal steroid excretion facilitates decreases in plasma cholesterol level [42]. Other health benefits associated with common beans may come from unidentified phytochemicals, such as phytoestrogens, antioxidants, and phenols, 


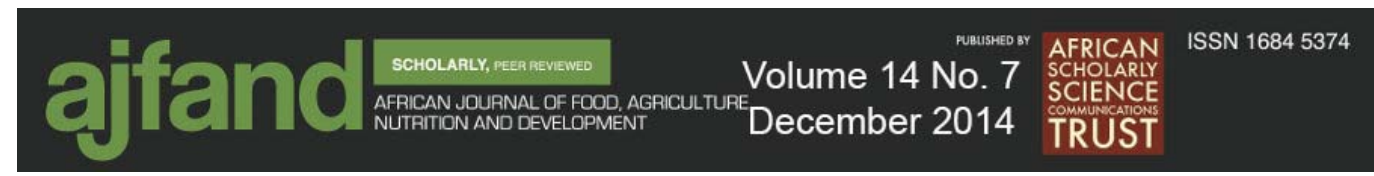

which together with vitamins and minerals such as vitamin $\mathrm{E}$ and selenium may play important roles in disease prevention [43, 44, 45, 46].

\section{Utilization of common beans}

In Africa and Latin American countries where common beans are staple foods, the seed are prepared by traditional cooking that involves boiling followed by the addition of various seasonings. In rural areas, the tradition cooking method is laborious as it requires large quantities of fuel in form of wood and enough water for boiling.

In order to increase the utilization of common beans in industrialized nations where most people opt for fast foods, processors in the food industry have come up with readyto-use products or products that are quick to prepare [1]. Categories of common beanbased products utilized in industrialized regions with wide market distribution channels include:

Canned beans: This processing method is widely practiced in both developing and developed regions. Canned bean market segment perhaps represent the greatest level of bean consumption in developed nations [1]. Beans are basically canned in tomato sauce and this product is widely accepted by the consumers. Pork and beans, which typically is canned in a tomato sauce with a small portion $(<2 \%)$ of pork, is one of the canned bean-based products with wide acceptance throughout the United States [1].

Pre-cooked and dehydrated bean flakes and powders: Instant pre-cooked bean powders prepared by soaking, cooking, slurrying and drum or spray drying of beans are feasible [47]. Fully-cooked dehydrated bean flakes, flours, formulated refried bean mixes and bean crumbles are commercially available in the United States of America market [1].

Pasta-type products: Attempts to include legume ingredients in the formulation of pasta products have been done by several workers. Fortified spaghetti prepared from blends of legume composite flours or protein concentrates demonstrated higher levels of protein, ash and fibre when compared to control spaghetti made from durum semolina [1]. Spaghetti supplemented with up to $10 \%$ legume flours or protein concentrates was judged acceptable by a taste panel [1]. Noodles prepared with pinto bean flour substituted at 5,10 and 20\% levels were tender and slightly darker; and increased substitution levels resulted in decreased flavour and acceptability [48].

Specialized food ingredients: Specialized pre-processed food ingredients possessing definitive and diversified functional properties have been prepared from dry edible beans [1]. High protein food ingredients can be produced as either flour fractions processed by pin milling $\&$ air classification, or as concentrates and isolates processed by alkali, salt and acid extraction with subsequent use of isoelectric precipitation or ultrafiltration [49]. Air classification of roasted beans produces high fiber, starch and protein fractions, each suitable as food ingredients in a variety of food products such as cookies, donuts, quick breads and leavened doughs [48]. 


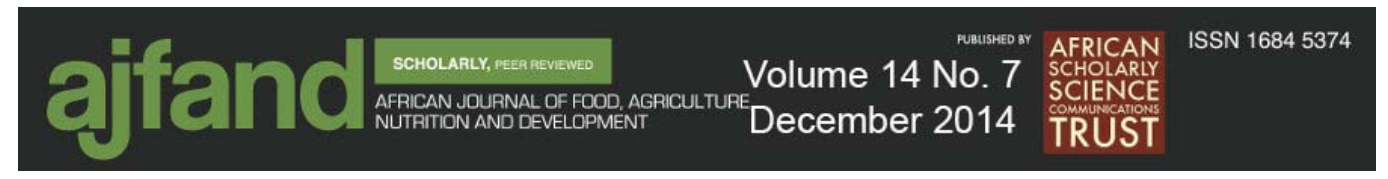

\section{CONCLUSION}

Common beans, undoubtedly has a very big potential for use as a nutraceutical food. Encouraging its consumption may help in the prevention of chronic diseases that are on the increase worldwide. Processing of common beans into a variety of products may increase the opportunities for its consumption. 


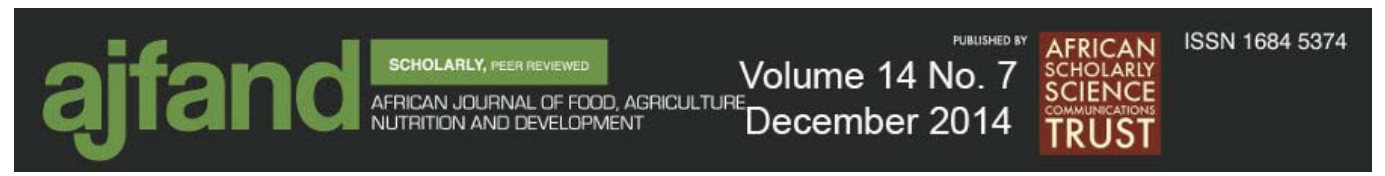

Table1: Chemical structures of selected phytochemicals identified in common beans

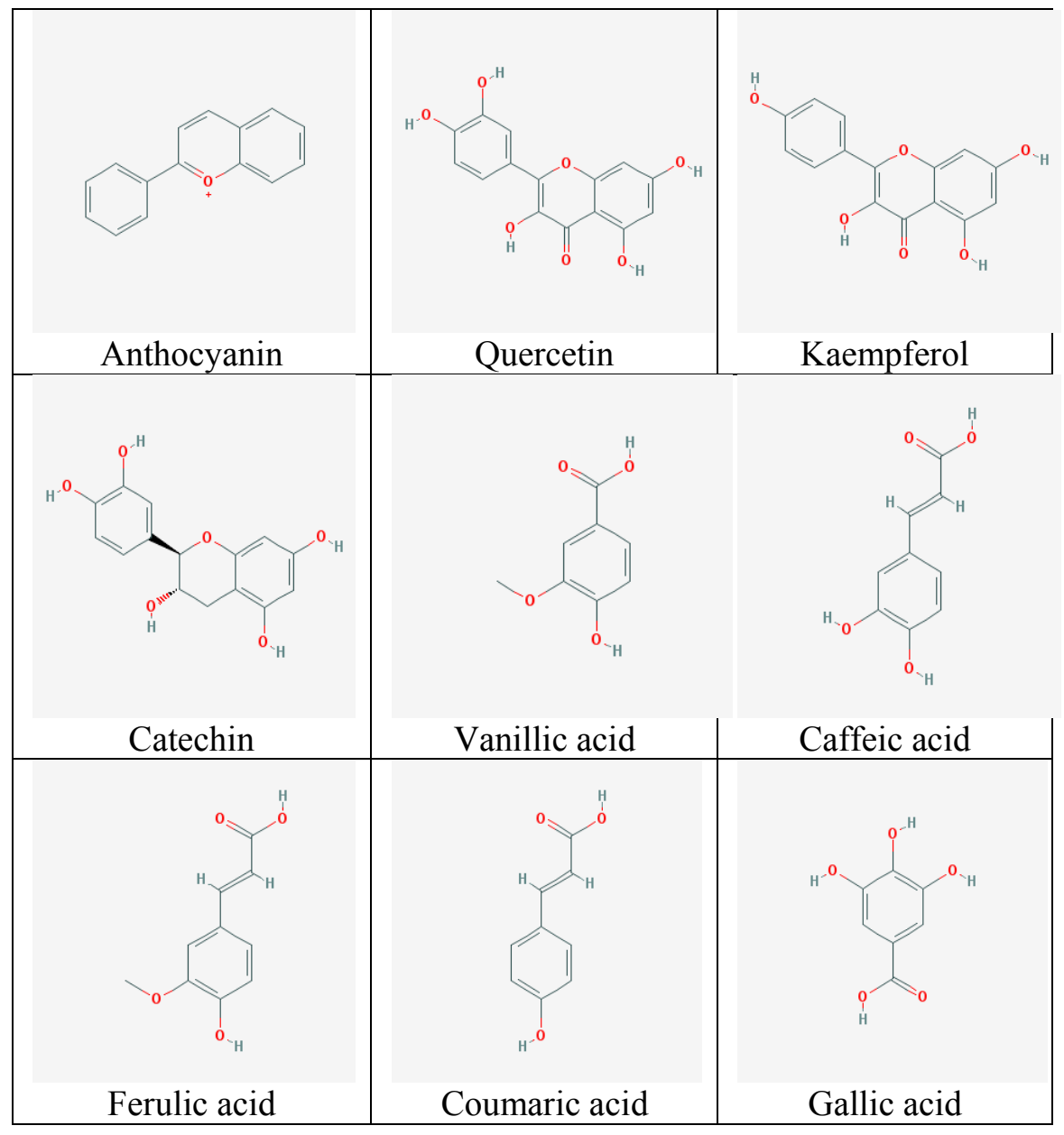

Adopted from Pubchem [50] 


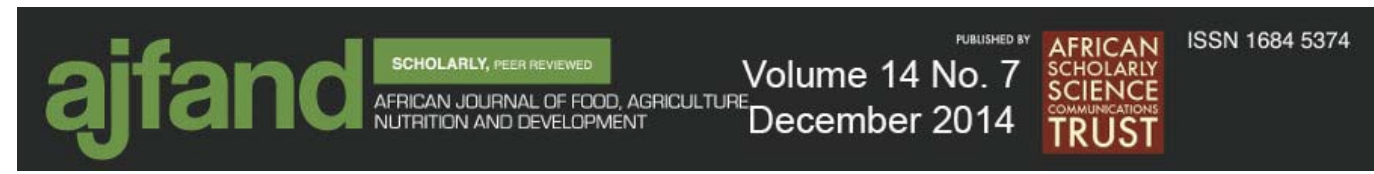

\section{REFERENCES}

1. Uebersax Dry Edible Beans: Indigenous Staple and Healthy Cuisine. The Forum on Public Policy, 2006.

2. Pachico D The demand for bean technology. In G. Henry (Ed.). Trends in CIAT commodities. Cali, Colombia: Centro International de4 Agricultura Tropical (CIAT), 1993.

3. Kushi LH, Meyer KA and DR Jacobs Cereals, legumes, and chronic disease risk reduction: evidence from epidemiologic studies. American Journal of Clinical Nutrition. 1999; 70: 451S-458S.

4. Ocho-Anin Atchibri AL, Brou1 KD, Kouakou TH, Kouadio YJ and D Gnakri Evaluation of bioactive components in seeds of Phaseolus vulgaris L. (fabaceae) cultivated in Côte d'Ivoire. Journal of Applied Biosciences. 2010; 31: $1928-1934$.

5. Joanne L, Slavin JL, Jacobs D, Marquart L and K Weimer The role of whole grains in disease prevention. J. Am Dietetic Assoc. 2001; 101: 780 - 785.

6. Adom KK, Sorrells ME and RH Liu Phytochemical profiles and antioxidant activity of wheat varieties. J. Agric. Food Chem. 2003; 51: 7825 - 7834.

7. Merrian-Webster dictionary Nutraceutical. In Merriam-Webster.com, retrieved February 25, 2013, from http://www.merriam-webster.com/dictionary/nutraceuticals.

8. Madhujith T, Amarowicz R and F Shahidi Phenolic antioxidants in beans and their effects on inhibition of radical-induced DNA damage. Journal of the American Oil Chemists' Society. 2004; 81: 691-696.

9. Beninger CW and GL Hosfield Antioxidant activity of extracts, condensed tannin fractions, and pure flavonoids from Phaseolus vulgaris L. seed coat color genotypes. J. Agric. Food Chem. 2003; 51: 7879-788 3.

10. Gabriela Espinosa-Alonso L, Anatoly L, Jack M, Widholm-Maria E, Valverde $M$ E, and $O$ Paredes-Lopez Polyphenols in Wild and Weedy Mexican Common Beans (Phaseolus vulgaris L.). J. Agric. Food Chem. 2006; 54: 4436-4444.

11. Miller H E, Rigelhof F, Marquart L, Prakash A and M Kanter Antioxidant content of whole grain breakfast cereals, fruits and vegetables. Journal of the American College of Nutri. 2000; 19(3): 312S-319S.

12. Patel JM A Review of Potential Health Benefits of Flavonoids. Lethbridge Undergraduate Research Journal. 2008; 3: (2). 


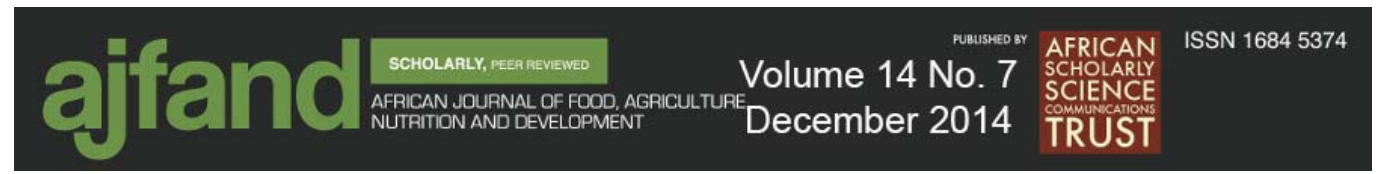

13. Hertog MG, Kromhout D, Aravanis, C, Blackburn H, Buzina R, Fidanza F, Giampaoli S, Jansen A, Menotti A, Nedeljkovic S, Pekkarinen M, Simic BS and $\mathbf{H}$ Toshima Flavonoid intake and long term risk of coronary heart disease and cancer in the seven countries study. Arch Intern Med. 1995; 155: 381-386.

14. Middleton E, Kandaswami $\mathbf{C}$ and TC Theoharides The Effects of Plant Flavonoids on Mammalian Cells: Implications for Inflammation, Heart Disease, and Cancer. Pharmacol. Rev. 2000; 52: 673-751.

15. Nijveldt RJ, Nood E, Hoorn D, Boelens PG, Norren $K$ and PA Leeuwen Flavonoids: a review of probable mechanisms of action and potential applications. Am J Clin Nutr. 2000; 74: 418-425.

16. Farkas L, Gabor M, Wagner $\mathbf{H}$ and $\mathbf{F}$ Kallay Flavonoids and Bioflavonoids. 1981; Amsterdam, Elsevier.

17. Pietta PG Flavonoids as Antioxidants. J Nat. Prod. 2000; 63: 1035-1042.

18. $\mathbf{Y u}$ L, Haley S, Perret $\mathbf{J}$, Harris $\mathbf{M}$, Wilson $\mathbf{J}$ and $\mathbf{M}$ Qian Free radical scavenging properties of wheat extracts. Journal of Agricultural and Food Chemistry. 2002; 50(6): 1619-1624.

19. Wu X L, Beecher GR, Holden JM, Haytowitz DB, Gebhardt SE and RL Prior Lipophilic and hydrophilic antioxidant capacities of common foods in the United States. J.Agric. Food Chem. 2004; 52: 4026-4037.

20. Cardador-Martínez A, Loarca-PiñanG and BD Oomahn Antioxidant activity in common beans (Phaseolus Vulgaris L.). J.Agric. Food Chem. 2002; 50: 6975-6980.

21. Hughes JS, Ganthavorn $\mathbf{C}$ and $\mathbf{S}$ Wilson-Sanders Dry beans inhibit azoxymethane-induced colon carcinogenesis in F344 rats. Journal of Nutrition. 1997; 127: 2328-2333.

22. Hangen $\mathbf{L}$ and MR Bennink Consumption of black beans and navy beans (Phaseolus vulgaris L.) reduced azoxymethane-induced colon cancer in rats. Nutrition and Cancer. 2002; 44(1): 60-65.

23. Cook SI and JI Sellin Review article: Short chain fatty acids in health and disease. Aliment Pharm Ther. 1998; 12: 499 - 507.

24. Manson MM, Gescher A, Hudson EA, Plummer SM, Squires MS and SA Prigent Blocking and Suppressing Mechanism of Chemoprevention by Dietary Constituents. Toxicology Lett. 2000; 112 - 113: $499-505$. 


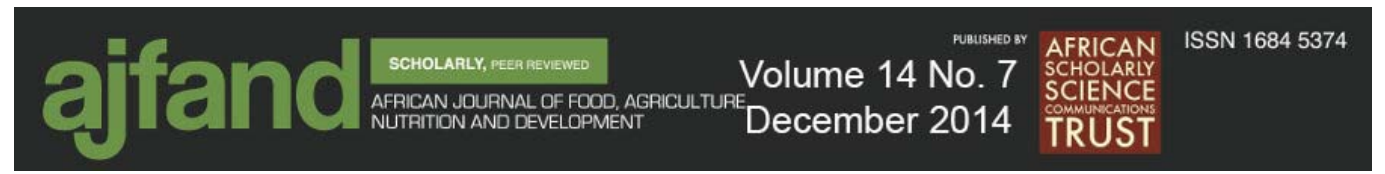

25. Klauning JE, Xu Y, Isenberg JS, Bachowski S, Kolaja KL, Jiang J, Stevenson DE and EF Walborg The role of oxidative Stress in Chemical carcinogenesis. Environ Health Persp. 1998; 106S: 289 - 295.

26. Frost G, Leeds A, Trew G, Margara R and A Dornhorst Insulin sensitivity in women at risk of coronary heart disease and the effect of a low glycemic diet. Metabolism. 1998; 47: 1245-51.

27. Wolever TMS, Jenkins DJA, Thompson L, Wong G and RG Josse Effect of canning on the blood glucose response bean in patients with type 2 diabetes. Human Nutrition: Clinical Nutrition. 1987; 41C: 135-140.

28. Tovar J, Sayago-Ayerdi SG, Penalver C, Paredes-Lopez $O$ and LA BelloPerez In vitro starch hydrolysis index and predicted glycemic index of corn tortilla, black beans (Phaseolus vulgaris L.), and Mexican taco. Cereal Chem. 2003; 80: 533-535.

29. Leathwood P and P Pollet Effects of slow release carbohydrates in the form of bean flakes on the evolution of hunger and saiety in man. Appetite. 1988; 10: $1-11$.

30. Hotamisligil $\mathbf{G}$ Inflammatory pathways and insulin action. International Journal of Obesity. 2003; 27: S53-S55.

31. Ludwig D Dietary glycemic index and obesity. J Nutr. 2000; 130: 280S-3S.

32. Jones JM, Reicks M, Adams J, Fulcher G and L Marquart Becoming proactive with the whole-grains message. Food Science Nutrition Today. 2004; 39: $10-18$.

33. Higgins JA Resistant Starch: Metabolic Effects and Potential Health Benefits. Journal of AOAC International. 2004; 87(3): 761-768.

34. Bazzano LA, He J, Ogden LG, Loria C, Vupputuri S, Myers L and PK Whelton Legume consumption and risk of coronary heart disease in US men and women. Archives of Internal Medicine. 2001; 161: 2573-2578

35. Hu FB, Rimm EB, Stampfer M J, Ascherio A, Spiegelman D and WC Willett Prospective study of major dietary patterns and risk of coronary heart disease in men. American Journal of Clinical Nutrition. 2000; 72: 912-921

36. Rifkind BM The Lipid Research Clinics coronary primary prevention trial results The relationship of reduction in incidence of coronary heart-disease to cholesterol lowering. Jama-Journal of the American Medical Association. 1984; 251: 365-374 


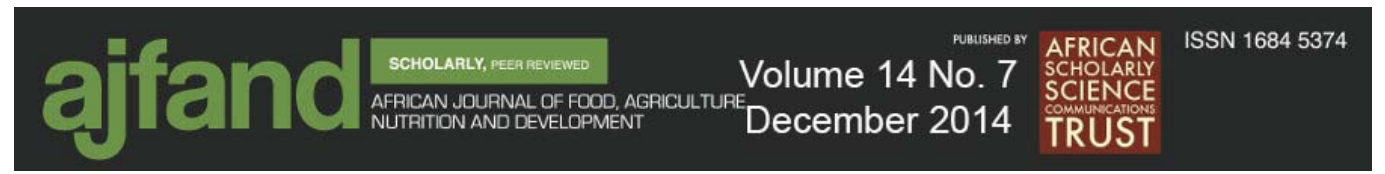

37. Anderson JW, Smith BM and NJ Gustafson Health benefits and practical aspects of high-fiber diets. American Journal of Clinical Nutrition. 1994; 59: S1242-S1247.

38. Shutler SM, Bircher GM, Tredger JA, Morgan LM and AF Walker The effect of daily baked bean (Phaseolus vulgaris L.) consumption on the plasma lipid levels of young, normo-cholesterolaemic men. Br. J. Nutr. 1982; 61: 257265.

39. Anderson JW, Story L, Sieling B, Chen WJL, Petro MS and J Story Hypocholesterolaemic effects of oat-bran or bean intake for hypercholesterolaemic men. Am. J. Clin. Nutr. 1984; 40: 1146-1155.

40. Brown L, Rosner B, Willett WW and FM Sacks Cholesterol lowering effects of dietary fibre: A meta-analysis. Am J Clin. (1999); 69: 30 - 42.

41. Moundras C, Behr SR, Remesy C and C Demigne Fecal losses of sterols and bile acids induced by feeding rats guar gum are due to greater pool size and liver bile acid secretion. J. Nutr. 1997; 127: 1068-76.

42. Han KH, Sekikawa M, Shimada K, Sasaki K, Ohba K and M Fukushima Resistant starch fraction prepared from kintoki bean affects gene expression of genes associated with cholesterol metabolism in rats. Exp. Biol. Med. 2004; 229: 787-92.

43. Reynoso-Camacho $\mathbf{R}$, Ramos-Gomez $M$ and $\mathbf{G}$ Loarca-Pina Bioactive components in common beans (Phaseolus vulgaris L.). Advances in Agriculture Biotechnology, 2006; 217-236 ISBN: 81-7736-269-0.

44. Slavin JL, Martin PC, Jacob D and L Maquart Plausible mechanism for protectiveness of whole grains. Am J Clin Nutr. 1999; 459S - 463S.

45. Miliauskas G, Venskutonis $\mathbf{P}$ and $\mathbf{T}$ van Beek Screening of radical scavenging activity of some medicinal and aromatic plant extracts. Food Chem. 2004; 85: 231-237.

46. Saura-Calixto F, Serrano J and I Goñi Intake and bioaccessibility of total phenols in a whole diet. Food Chem. 2007; 101: 492-501.

47. Bakker RW, Patterson RJ and CL Bedford Production of instant bean powders. Nutrtional Aspects of Common Beans and other Legume Seeds as Animal and Human foods. Jaffe, W (ed.) Archoivos Latinoamericanos de Nutrticion, Caracas, Venezuela. 1973.

48. Uebersax MA and ME Zabik Processing and use of dry edible bean flours in foods. Referred Chapter 16: Plant Proteins: Applications, Biological Effects, and Chemistry. ACS Symposium Series 312, Amer. Chem. Soc., Washington, D.C. $1986 ; 190-205$. 


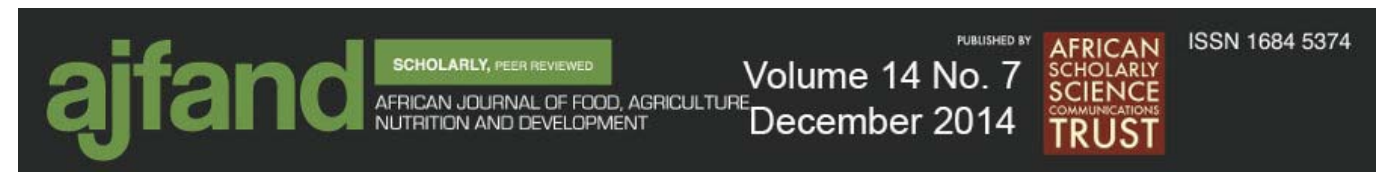

49. Uebersax MA, Ruengsakulrach S and LG Occena Stratergies and procedures for processing dry beans. Food Technol. 1991; 45(9): 104-108, 110-111.

50. Pubchem. Pubchem. compounds. Available from http://pubchem.ncbi.nlm.nih.gov accessed on 23 ${ }^{\text {rd }}$ January 2013. 